\title{
Impact assessment of the incorporation of the rotavirus vaccine in the province of San Luis - Argentina- CORRIGENDUM
}

\section{Corrigendum}

Cite this article: García Martí S, Augustovski F, Gibbons L, Loggia V, Lepetic A, Gómez JA, Riviere AP (2019). Impact assessment of the incorporation of the rotavirus vaccine in the province of San Luis - Argentina-

CORRIGENDUM. Epidemiology and Infection 147, e320, 1. https://doi.org/10.1017/

S0950268819002164
S. García Martí, F. Augustovski, L. Gibbons, V. Loggia, A. Lepetic, J.A. Gómez and A. Pichón Riviere

DOI: 10.1017/S0950268819001936, Published online by Cambridge University Press, 27 November 2019

The above paper was originally submitted to Epidemiology \& Infection with the indication that A. Pichón Riviere's surname should be indexed as 'Riviere, AP' instead of 'Pichón Riviere, A.' and was originally published as such.

This has been rectified in the online PDF and HTML copies and re-indexed accordingly.

\section{Reference}

García Martí S., Augustovski F., Gibbons L., Loggia V., Lepetic A., Gómez J., \& Pichón Riviere A. (2019). Impact assessment of the incorporation of the rotavirus vaccine in the province of San Luis - Argentina. Epidemiology and Infection, 147, E308. doi:10.1017/S0950268819001936 (c) GlaxoSmithKline 2019. This is an Open Access article, distributed under the terms of the Creative Commons Attribution licence (http://creativecommons.org/licenses/by/4.0/), which permits unrestricted re-use,

distribution, and reproduction in any medium, provided the original work is properly cited.

\section{CAMBRIDGE UNIVERSITY PRESS}

